\title{
Reading Performance in Adults with Intellectual and Developmental Disability (IDD) When They Read Different Kinds of Texts
}

\author{
Jose A. León ${ }^{\mathrm{a}^{\star}}$, Alvaro León-López ${ }^{\mathrm{b}}$ \\ ${ }^{a}$ Universidad Autónoma de Madrid, Madrid, Spain \\ ${ }^{b}$ Universidad de Alcalá, Alcalá de Henares, Spain \\ ${ }^{\star}$ Corresponding author. E-mail: joseantonio.leon@uam.es
}

Background. Over the last several decades, the world has been made more accessible for people with disabilities. However, many of these achievements have primarily focused on physical limitations, and it is also important that the environment be made easy to understand for those people who may be at risk of social exclusion. Reading competence is one of the fundamental functional skills people need to access communication and culture. The facilitation of this adaptation is called cognitive accessibility. Cognitive accessibility encompasses everything related to how people understand the meaning of their environment, and especially written documents.

Objective. The main objective of this study was to establish a scale of evaluation of reading competence for adults with intellectual and developmental disability (IDD) compared to university students (as a control group). Thus, we sought to establish different levels of reading competence relative to the difficulty of various texts (A, B, C), in accordance with the criteria established in the Common European Framework of Reference for Languages (CEFR).

Design. 450 adults with IDD and 200 undergraduate university students took part in this study. They read and were scored on three texts of different lexical and semantic complexity.

Results. The results in three different studies showed that adults with intellectual and developmental disability (AIDD) improve their performance in reading comprehension when additional time and support are made available.

Conclusion. If a greater amount of time is made available, the performance of a significant part of the AIDD population improves considerably, in some cases approaching the level of performance of university students. These results raise new lines of research on how to give people with IDD access to more comprehensible and accessible reading material.

Keywords: Intellectual and Developmental Disability (IDD); Adults with Intellectual and Developmental Disability (AIDD); text comprehension; reading performance; reading comprehension; text complexity 


\section{Introduction}

Intellectual and Developmental Disability (IDD) is defined as a significant impairment in general cognitive functioning, social skills, and adaptive behavior (Schalock, Borthwick-Duffy, \& Bradley, 2009; Shapiro, \& Batshaw, 2013). The Diagnostic and Statistical Manual of Mental Disorders-Fifth Edition (DSM-5) defines it as deficits in intellectual functions such as reasoning, problem solving, planning, abstract thinking, judgment, academic learning, and learning from experience. Deficits in such adaptive functions affect communication, social participation, and independent living activities (Patel, Greydanus, \& Merrick, 2016). The prevalence of intellectual disability is estimated at $1 \%$ in the general population. While most of these individuals have mild intellectual disability, six per 1,000 individuals have severe intellectual disability.

In Spain, an assessment of intellectual and developmental disability is carried out in each Autonomous Community; a few parameters are applied to measure the type of disability, the limitations it imposes on daily life or the person's level of adaptability, and other social factors that limit these individuals' participation in society. The fulfillment of the rights of people with intellectual and developmental disabilities is a major national objective, as can be seen in the records of the Institute for the Elderly and Social Services (IMSERSO). That database (2017) registered 268,633 people with IDD at the end of 2015. Their levels of intellectual disability were classified into three categories: Mild (from 33\% to 50\% grade of IDD); Moderate (from $51 \%$ to $70 \%$ grade of IDD); and Severe (more than $71 \%$ grade of IDD).

For several decades, progress in creating a more accessible world for people with disabilities has been heralded, and many achievements have indeed been made. However, many of these achievements have primarily focused on physical or space limitations (such as architectural barriers, the adequacy of public transportation, pedestrian access to public roads or ramp location). But it is also important to make the total environment easy for all people to understand, and especially those people who may be at risk of exclusion (social, cultural, or informative). Within these risk groups are adults with IDD.

The ability to understanding information is one of the fundamental functional skills people need in order to access communication and culture. The facilitation of this adaptation to the environment is carried out through what is called cognitive accessibility. Cognitive accessibility encompasses everything related to how people understand the meaning of their environments, objects, information, news, or any written document. In general, it is said that something is cognitively accessible when it is comprehensible or easy to understand. Enhancing cognitive accessibility has the primary objectives of allowing people to understand the environment in which they live; to understand everything that they relate to; and to determine whether the people, objects, or information with which they are involved can be more efficient with respect to their well-being and quality of life (Belinchón, Casas, Díez, \& Tamarit, 2014). This capability allows people to be better informed, improves their social participation, and facilitates their social and cultural inclusion. All this positively affects people's emotional, social, and participatory well-being.

Reading comprehension is one of the fundamental pillars within this general framework of cognitive accessibility. One application is called "Easy Reading" (For a complete review, see García Muñoz, 2012). Easy Reading is a tool that allows texts 
to be adapted to a simpler written form, with the aim of facilitating understanding by people who do not have a habit of reading. These adaptations are made in books, administrative and legal documents, and news and web pages, as well as in many other types of documents. Easy Reading follows the criteria established in Inclusion Europe, which set European guidelines for making information easy to read (see http://www.plenainclusion.org/sites/default/files/informaciontodos.pdf).

But this line of work is very limited, since more than $80 \%$ of the writing published in any medium is written at high competence levels (such as B2 and C1), and adaptation to more accessible levels would be very expensive and practically impossible. Furthermore, although there is a general assumption that people with IDD would not be able to understand texts that feature any lexical or syntactic difficulty, there are no empirical studies which have researched the reading competence of this group. Therefore, we undertook three research projects in Spain in order to study the improvement of reading comprehension and competence in adults with IDD by analyzing their cognitive accessibility within a particularly useful and necessary context. These were done in the Madrid Community (León, Jastrzebska, \& Martínez-Huertas, 2018), the Extremadura Community, and Andalusia (León, Jastrzebska, Martínez-Huertas \& León-López, 2019).

One way to generate texts with different levels of difficulty is to adapt them according to the criteria established in the Common European Framework of Reference for Languages (CEFR). The CEFR measures language proficiency on a six-level scale (A1, A2, B1, B2, C1, and C2). These can be regrouped into three broad levels: Basic User (Easy), Independent User (Intermediate), and Proficient User (complex texts), and each can be further subdivided according to the local context. The CEFR has developed a description of the process of mastering an unknown language by type of competence and sub-competence, using descriptors for each; we shall not go into further detail here. These descriptors were created without reference to any specific language, which guarantees their relevance and across-the-board applicability. The descriptors specify progressive mastery of each skill in Spanish in the Curriculum Plan of the Cervantes Institute (https://cvc.cervantes.es/ensenanza/biblioteca_ele/marco/cvc_mer.pdf; https://www.coe.int/en/web/language-policy/home).

A large number of authors have investigated and agreed on the relationship between texts with different levels of difficulty, and the two different levels of mental representation that directly affect comprehension and competence in reading: the text-based model and the mental or situational model (e.g., Gernsbacher, Varner, \& Faust, 1990; Graesser, León, \& Otero, 2002; Kintsch, 1988, 1998; León, 2004a; León \& Escudero, 2015; van den Broek, Rapp, \& Kendeou, 2005; van Dijk \& Kintsch, 1983). The text-based model concerns all kinds of tasks that require understanding, but is always related to the presentation of explicit information from the text (León et al., 2012). A standard task on the text-based level is searching or locating specific information in the text, or searching for relationships or connections between different parts of the text. The mental model, on the other hand, is considered to be a more complex representational level, since it requires a considerable contribution from the reader's knowledge and the drawing of inferences. (León \& Escudero, 2017). The model of reading comprehension that is assumed here takes into account that there are differences between the types of comprehension and types of text (León, 1996; León, 2004b; León, Escudero, \& Olmos, 2012). 


\section{Objective}

The main objective of this study was to establish a scale of evaluation of reading competence for adults with IDD in comparison with university students (as a control group), using as references three Autonomous Communities: Madrid, CastillaLa Mancha, Andalusia, and Extremadura. We sought to establish different levels of reading competence related to the difficulty of texts $(A, B, C)$ that exemplify the criteria established in the Curriculum Plan of the Cervantes Institute (PCIC) and the Common European Framework of Reference for Languages (CEFR). In this way, relationships are established between the characteristics of the text, or source of information, with the cognitive skills, reading strategies, and contexts in which they occur, in the different groups studied. More specifically, the objectives set out in this study consisted of answering the following three groups of questions:

1. How do people with intellectual or developmental disabilities read and understand texts? How is their performance affected by the degree of complexity of the text?

2. How similar are the reading competencies of adults with intellectual disabilities to the development of university adults? And how are they different?

3. Are there differences between people with intellectual or developmental disabilities depending on their degree of disability? In other words, does the degree of intellectual disability determine the level of reading competence?

\section{Method}

\section{Participants}

A total of 450 adults with IDD (mean age of 37 years, a range of 20-62 years, and a medium disability degree $=64, \mathrm{SD}=12$ ), and 205 undergraduate university students (mean age of 22 years) took part in this research. Approximately fifty percent of the participants were female. The reading performance of the university students was used as a reference (control) to compare with the reading performance of the adults with IDD.

\section{Materials}

Participants read three texts on different topics and with different levels of lexical and linguistic complexity (A, B, and C). The International Federation of Library Associations and Institutions (IFLA) proposes the use of three levels of complexity which are not linked to the levels established in texts for language learning:

- Level I: The easiest, with many illustrations and little text, which text has simple syntactical and linguistic structures.

- Level II: With vocabulary and expressions from everyday life, easy-to-follow actions, and illustrations.

- Level III: The most complex, with longer texts, some unusual words, spacetime breaks, and very few illustrations. 
Following the conceptual framework above, we tried to unify the linguistic criteria (of the base text) with the semantic aspects (of content, based on the understanding). Complementarily, these texts were compared with a text from the standardized reading comprehension assessment test ECOMPLEC.Sec (León et al., 2012), in order to compare the reading comprehension competence of the adults with IDD with the university student group.

\section{Procedure}

The same procedure was applied at all the stages of these research projects. Specifically, these tasks were applied collectively to different samples of adults with IDD. First, a general explanation was given to every group of participants. We started the study once the people responsible for helping the participants were sure that the participants understood the instructions. Then, the participants read different combinations of the texts. They read the texts individually and were asked to answer different multiple-choice questions. All the participants had unlimited time to answer all the questions.

\section{Results}

The following different aspects of the results were analyzed: 1) External validity and the results using the standardized ECOMPLEC test; 2) the reading performance by the participants with IDD and the university students, in texts with different levels of difficulty; and 3) the reading performance relative to different levels of IDD (mild, moderate, or severe) in texts with different levels of difficulty $(A, B$, and $C)$.

\section{External validity and results using the standardized ECOMPLEC test}

Before analyzing the texts' complexity, a standardized test of reading comprehension (ECOMPLEC.Sec) with a high complexity level $(\mathrm{C} 1-\mathrm{C} 2)$ was given in order to compare the reading performance of the two groups (adults with IDD and university students) in a pilot study. A total of 63 of the university students obtained an average of $.86(\mathrm{SD}=.11)$; and 68 adults with IDD scored an average of .39 $(\mathrm{SD}=.13)$. Thus, the difference in means between both groups was very large and significant $(\mathrm{t}=-22.264, \mathrm{gl}=126.056, \mathrm{p}<.01)$. However, as shown in Figure 1, there was a notable overlap in the performance of both groups; that is, there

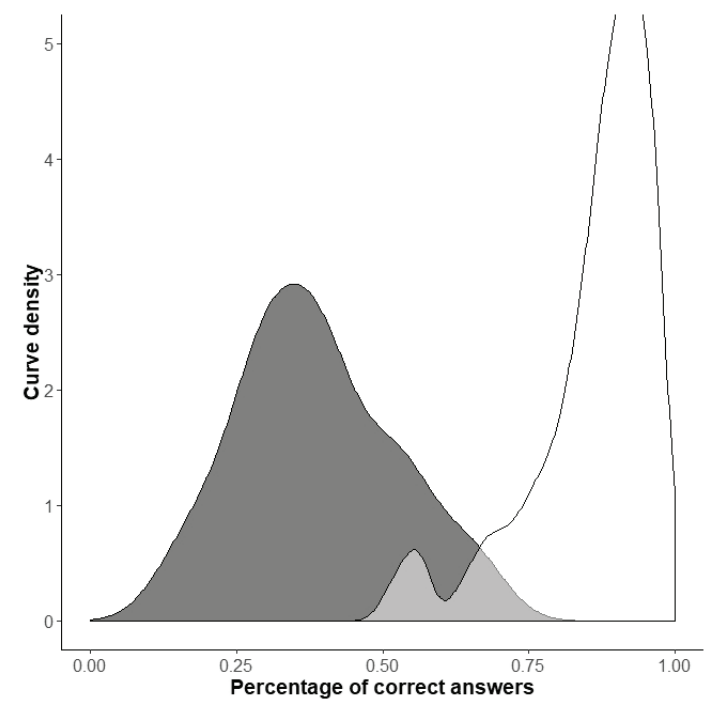

Figure 1. Density curves in the ECOMPLEC Standard test comparing AIDD (black) and university groups (white).

Note. Each of the curves represents the number of people who have obtained a certain percentage of hits (range 0-1) (adapted from León et al., 2018) 
were people with intellectual disabilities who even surpassed some of the university students (specifically, the range of performance of people with intellectual or developmental disabilities was .12-.70, compared to the range of university students, which was .52-1.00).

\section{Reading performance between adults with IDD and university group in texts with levels different difficulty $(A, B$, and $C)$}

It is assumed as a criterion for this analysis that a participant reaches a level of competence when his or her performance exceeds $60 \%$ on the test, within each level of difficulty of the text (A, B, and $\mathrm{C}$ ). To calculate the data, a descriptive analysis of the levels of competence of the sample in this study was carried out. The results are shown in Figure 2.
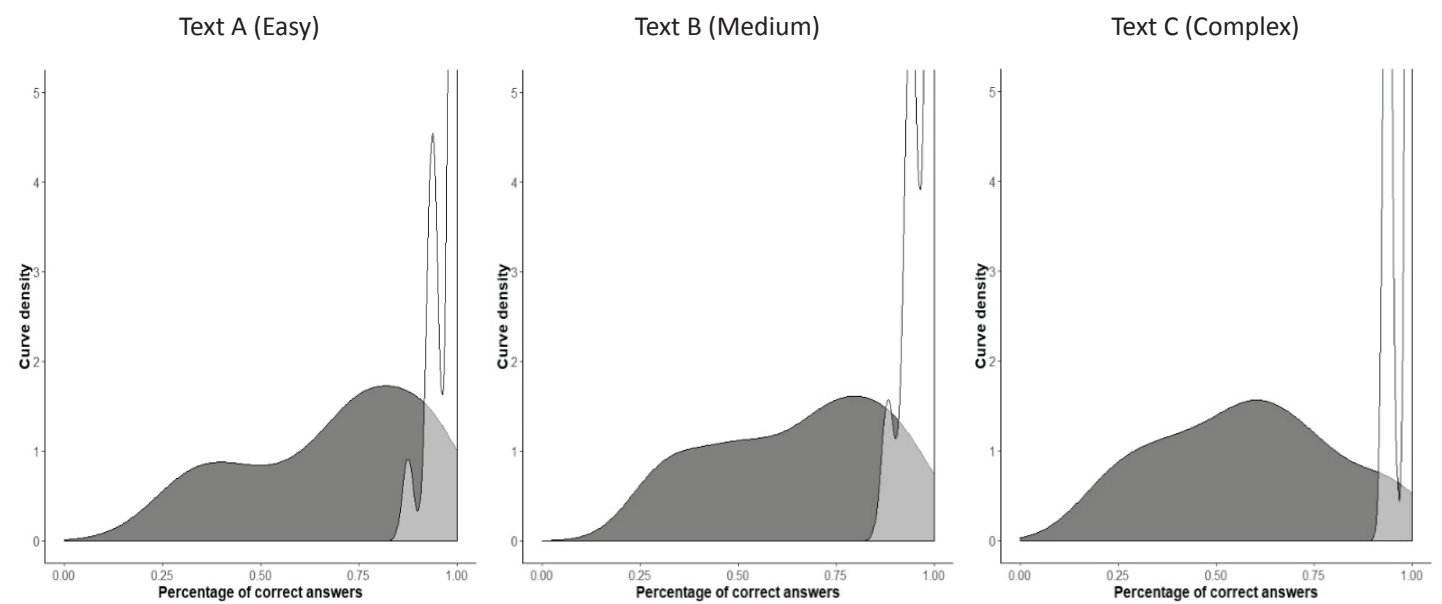

Figure 2. Density curves in the tests comparing reading performance between adults with IDD Group (in black) and the university student group (white) in texts with different difficulty.

Note. Each of the curves represents the number of people who have obtained a certain percentage of hits (range 0-1) (adapted from León et al., 2018).

Although all the differences were statistically significant, when the performance of both groups was compared $(\mathrm{p}<.01)$, there was a huge spread in the performance of the adults with IDD. As can be seen in Figure 2, there was an inverse relationship between the difficulty of the text ( $\mathrm{A}, \mathrm{B}$ and $\mathrm{C})$ and reading performance by the participants. In this way we can show that the easier the text was, the more participants reached a level of reading competence suitable for that level. And vice versa: the more difficult the text was, the fewer people reached a level of reading competence suitable for that more complex level. Thus, on the easiest text (text A), which is similar to the texts of Easy Reading, 70\% of the adults with IDD obtained a sufficient level of reading competence. On the intermediate level (B), the percentage of people with IDD who passed the test was 53\%. However, only $20 \%$ of the people with IDD who participated in this study managed to reach a C level of reading competence. 


\section{Analyzing the influence of the degree of disability on reading performance}

In this section we analyzed the influence of the degree of disability (mild, moderate, and severe) on the performance at the different levels of difficulty of the text $(\mathrm{A}, \mathrm{B}$, and C) through a univariate ANOVA (see Table 1).

Table 1

Reading Performance according to the degree of IDD of the participants (Mild, Moderate and Severe) in the different difficulty levels of the texts $(A, B$, and $C)$

\begin{tabular}{clccc}
\hline \multirow{2}{*}{$\begin{array}{c}\text { Text } \\
\text { Difficulty }\end{array}$} & Effect & \multicolumn{2}{c}{ Differences relative to the degree of IDD } \\
\cline { 3 - 5 } & & $\begin{array}{c}\text { Mild }- \\
\text { Moderate }\end{array}$ & $\begin{array}{c}\text { Mild }- \\
\text { Severe }\end{array}$ & $\begin{array}{c}\text { Moderate }- \\
\text { Severe }\end{array}$ \\
\hline A & $\mathrm{F}(2,348)=7.83, \mathrm{p}<.01, \eta^{2}=.04$ & $\mathrm{p}<.01$ & $\mathrm{p}<.01$ & $\mathrm{NS}$ \\
B & $\mathrm{F}(2,340)=5.20, \mathrm{p}<.01, \eta^{2}=.03$ & $\mathrm{p}<.01$ & $\mathrm{p}<.01$ & $\mathrm{NS}$ \\
C & $\mathrm{F}(2,318)=8.57, \mathrm{p}<.01, \eta^{2}=.05$ & $\mathrm{p}<.01$ & $\mathrm{p}<.05$ & $\mathrm{p}<.05$ \\
\hline
\end{tabular}

Note. The differences between groups have been calculated from pairwise comparisons of the effects of univariate ANOVA. These multiple comparisons have been corrected with Bonferroni.

The effect of the degree of disability was statistically significant at all levels of difficulty. However, the chief differences that were found occurred between the group with mild disability, versus those with moderate and severe disabilities (while these last two groups do not show differences between them). It is interesting to note that the only significant differences between the groups with moderate and severe disability were found at level of difficulty C (again, see Table 1).

\section{Discussion}

Our first finding is that there was a great variability within the AIDD group in performance on the reading competence tests, regardless of the level of text complexity. As far as reading competence is concerned, it is also important to note that the same material can be very easy or very difficult for two subjects diagnosed with a similar degree of intellectual disability. With regard to the comparison in reading comprehension and competence between the two groups (AIDD and university students), a good level of reading competence was detected in general, although, as expected, there were great differences between the groups.

Perhaps the most surprising fact is that there was a clear overlap between the groups. There were participants from the AIDD group whose performance equaled or even surpassed that of the university adults in the tests (even in very difficult tasks, such as the text of the ECOMPLEC standardized test).

There are several factors that can explain the considerable overlap between both groups. A determining factor for interpreting the results obtained by the AIDD group against the group of university students was time. The university students took 36 minutes on average to complete all the tests, while the AIDD took 109 
minutes, almost three times longer. Thus, it can be said that time is a good ally in facilitating understanding by AIDD. When no time limitation is imposed - that is, when they have enough time to understand the materials - high performance can be achieved on the tests. Thus, AIDD can achieve very high levels of performance when they have the necessary resources (in this case, more time and support), thus compensating for some of their cognitive limitations. AIDD have the potential to improve if they have adequate support or opportunities.

\section{Conclusion}

One important conclusion of this study is that adults with IDD are sensitive to the difficulty of the texts and that they have shown a level of reading skills much higher than expected. In fact, their level of reading proficiency is not limited to the comprehension of very simple texts (Level A) as it was believed, but an important proportion of the participants were able to understand texts with a level of medium or high complexity (B or $\mathrm{C}$ ). This result allows us to consider that their reading skills can be improved both by adjusting the levels of the texts, making them more attractive, and by improving AIDD's reading strategies through establishing specific reading workshops for them.

In this sense, the Easy Reading program is considered a necessary but not sufficient tool for making the world more accessible for AIDD. From the perspective of the current approaches to reading, Easy Reading follows a bottom-up procedure that involves the adaptation of materials and their reading based on the aspects most related to lexical and semantic simplification. That is to say, the contents and the syntactic and grammatical structures are reduced; the more technical words are replaced by more common ones; and parts of the information are eliminated because they are considered too complex, etc., in order to make them easier and more accessible.

However, many of the strategies proposed to improve the understanding of adults with IDD have been questioned. For example, different authors have shown that the positive effects of some Easy Reading rules are not clear (e.g., Chinn \& Homeyard, 2016; Sutherland \& Isherwood, 2016), and some studies show that the combination of texts or images which have been edited according to Easy Reading rules, do not make them more understandable than the original materials (Hurtado, Jones, \& Burniston, 2014). Although these proposals are of great social importance, a necessary step for developing useful tools to improve the understanding of adults with IDD is the investigation of these psychological processes from an operational theoretical framework of reading comprehension.

\section{Limitations}

Our important finding of variability in the reading performance of the sample of adults with IDD has some limitations. There were people who obtained a hit ratio of 0 , while other people in the same group got a hit ratio of 1 (that is, there were people who didn't answer any questions and others who answered all the questions). This result should lead us to establish a framework that takes into account 
the enormous variability of performance in the different tasks shown by adults with IDD because 1) the same material can be very easy or very difficult for the same sample group; and 2) future research is likely to focus on more homogeneous groups of people with intellectual or developmental disabilities, to maximize the results of the study of what support needs to be provided. This last aspect does not refer to homogenizing a future sample, but to collecting more information about the participants so as to be able to make more groupings. Thus researchers will be able to check whether there are some variables that can provide more information than others in order to understand how reading comprehension works, and what aspects can be improved (e.g., These variables might include whether people have previously worked on easy reading; their family's reading habits; whether or not they take medication; and whether they have been involved in inclusive contexts or not, etc.). Such information can be relevant for grouping people.

\section{Practical implications}

Independent of all these variables, all the AIDD who participated in this study have a margin for improvement in their reading performance and in the development of their reading strategies. AIDD with high degrees of disability, or with very basic skills, are able to improve their reading performance when they have the time they need or are motivated by the task. A greater degree of motivation can be developed through the improved design of texts, by the inclusion of images and graphics that complement written information, and the use of humor, emotion, and sarcasm (León, 1999; León \& Carretero, 1992). This type of design could increase both the interest in reading and the development of strategies related to improving reading competence.

\section{Acknowledgements}

This research was supported by ONCE Foundation of Basic Research and Plena inclusión Spain (Projects No.044602, 044603, and 044601).

\section{References}

Belinchón, M., Casas, S., Díez, C., \& Tamarit, J. (2014). Accesibilidad cognitiva en los centros educativos. Guías prácticas de orientaciones para la inclusión educativa. Ministerio de Educación, Cultura y Deporte.

Chinn, D., \& Homeyard, C. (2016). Easy read and accessible information for people with intellectual disabilities: Is it worth it? A meta-narrative literature review. Health Expectations, 20(6), 1189-1200. https://doi.org/10.1111/hex.12520

García Muñoz, O. (2012). Lectura fácil: Métodos de redacción y evaluación. Madrid: Real Patronato sobre Discapacidad.

Gernsbacher, M.A., Varner, K.R., \& Faust, M.E. (1990). Investigating differences in general comprehension skill. Journal of Experimental Psychology: Learning, Memory, and Cognition, 16(3), 430-445. https://doi.org/10.1037//0278-7393.16.3.430

Graesser, A.C., León, J.A., \& Otero, J.C. (2002). Introduction to the psychology of science text comprehension. In J.C. Otero, J.A. León, \& A.C. Graesser (Eds.), The psychology of science text comprehension (pp. 1-15). Mahwah, NJ: Lawrence Erlbaum Associates. 
Hurtado, B., Jones, L., \& Burniston, F. (2014). Is Easy Read information really easier to read? Journal of Intellectual Disability Research, 58(9), 822-829. https://doi.org/10.1111/jir.12097

IMSERSO (2015). Base Estatal de datos de personas con discapacidad. http://www.imserso.es/imserso_01/documentacion/estadisticas/bd_estatal_pcd/index.htm

Kintsch, W. (1988). The use of knowledge in discourse processing: A construction-integration model. Psychological Review, 95, 163-182. https://doi.org/10.1037/0033-295X.95.2.163

Kintsch, W. (1998). Comprehension: A paradigm for cognition. Cambridge University press.

León, J.A. (1996). Prensa y Educación. Un enfoque cognitivo. Buenos Aires: Aique.

León, J.A. (1999). Mejorando la comprensión y el aprendizaje del discurso escrito: estrategias del lector o estilos de escritura. In J.I. Pozo \& C. Monereo (Coords.), El aprendizaje estratégico (pp. 153-170). Madrid: Santillana.

León, J.A. (2004a). ¿Por qué las personas no comprenden lo que leen? Psicología Educativa, 10(2), $101-116$.

León, J.A. (2004b). Un nuevo enfoque en la competencia lectora basado en diferentes tipos de comprensión. Seminario de primavera 2004, Fundación Santillana, 39-50.

León, J.A. \& Carretero, M. (1992). Signals effects on the recall and understanding of expository texts in expert and novice readers. In A. Oliveira (Ed.), Hypermedia Courseware: Structures of Comunication and Intelligent Help (pp. 97-111). New York: Springer-Verlag. https://doi.org/10.1007/978-3-642-77702-8_12

León, J.A. \& Escudero, I. (2015). Understanding Causality in Science Discourse for Middle and High School Students. Summary task as a Strategy for Improving Comprehension. In K.L. Santi and D. Reed (Eds), Improving Comprehension for Middle and High School Students (pp. 75-98). Springer International Publishing Switzerland. https://doi.org/10.1007/978-3-319-14735-2_4

León, J.A. \& Escudero, I. (2017). Causal inferences in reading comprehension: State of the art. En J.A. León \& I. Escudero (Eds.), Reading comprehension in educational settings. Series of Studies in Written Language and Literacy (pp. 63-99). Amsterdam: John Benjamins Publishing Company. https://doi.org/10.1075/swll.16.03leo

León, J.A., Escudero, I., \& Olmos, R. (2012). ECOMPLEC. Evaluación de la comprensión lectora. Madrid: TEA Ediciones.

León, J.A., Martínez-Huertas, J.A, Jastrzebska, O., \& León-López, A. (2019). Informe nacional del proyecto sobre la competencia lectora de personas adultas con Discapacidad Intelectual y del Desarrollo (DID). Plena inclusión. https://doi.org/10.5093/clysa2018a17

León, Jastrzebska, \& Martínez-Huertas (2018). Informe del Proyecto "Escalas de competencia lectora en la Comunidad de Madrid" ¿Cómo comprendemos lo que leemos? Retrieved from https://www.plenainclusion.org/sites/default/files/plena_inclusion_-_informe_investigacion_ escalas_de_comprension.pdf

León, J.A., Martínez-Huertas, J.A., \& Jastrzebska, O. (2018). Un estudio sobre la competencia lectora en adultos con discapacidad intelectual y del desarrollo ante textos con contenidos de clínica y salud. Clínica y Salud, 29, 115-123. https://doi.org/10.5093/clysa2018a17

Patel, D.R., Greydanus, D.E., Merrick, J., et al. (2016). Introduction to intellectual and developmental disabilities. In I.L. Rubin, J. Merrick, D.E. Greydanus, et al. (Eds.). Health care for people with intellectual and developmental disabilities across the lifespan (pp. 5-14). Dordrecht: Springer. https://doi.org/10.1007/978-3-319-18096-0_1

Schalock, R.L., Borthwick-Duffy, S.A., Bradley, V., Buntix, W.H.E., Coulter, M.D., Craig, E.M., \& Yeager, M.H. (2009). Intellectual disability. Definition, Classification, and Systems of Supports. 11th Edition. Washington, D.C.: American Association on Intellectual and Developmental Disabilities.

Shapiro, B.K, \& Batshaw, M.L. (2013). Developmental delay and intellectual disability. In M.L Batshaw, L. Pellegrino, N.J. Roizen (Eds.). Children with Disabilities, 7th edition, (pp. 291-306). Baltimore: Paul Brookes. 
Sutherland, R.J., \& Isherwood, T. (2016). The Evidence for Easy-Read for People With Intellectual Disabilities: A Systematic Literature Review. Journal of Policy and Practice in Intellectual Disabilities, 13(4), 297-310. https://doi.org/10.1111/jppi.12201

van den Broek, P., Rapp, D.N., \& Kendeou, P. (2005). Integrating memory-based and constructionist processes in accounts of reading comprehension. Discourse processes, 39(2-3), 299-316. https://doi.org/10.1080/0163853X.2005.9651685

van Dijk, T.A. \& Kintsch, W. (1983). Strategies of discourse comprehension. New York: Academic Press.

Original manuscript received August 06, 2019

Revised manuscript accepted October 25, 2019

First published online December 25, 2019

To cite this article: Leon, J.A., León-López, A. (2019). Reading Performance in Adults with Intellectual and Developmental Disability (IDD) When They Read Different Kinds of Texts. Psychology in Russia: State of the Art, 12(4), 148-158. DOI: 10.11621/pir.2019.0409 